\title{
Radioactivity studies on 2 synovial specimens after radiation synovectomy with yttrium-90 silicate
}

\author{
P. B. DUNSCOMBE AND N. W. RAMSEY \\ From the Department of Medical Physics, Charing Cross Hospital, London
}

SUMMARY Synovial membranes surgically removed from the knees of 2 patients who had received radioactive yttrium-90 silicate have been examined. Autoradiographs showed that in both cases the activity was unevenly distributed over the synovium. One of the specimens, removed 7 weeks after administration of the isotope, was found to contain a slight degree of radioactivity, attributable in part to a long-lived radioactive contaminant.

The optimum therapeutic benefit from the use of radioactive colloids in the treatment of rheumatoid arthritis will be obtained if the isotope covers the whole of the synovial membrane and if the rate of loss of the colloid from the joint is low. In the case of the knee it is believed from scanning studies that a satisfactory distribution of the colloid occurs within a few hours (Prichard et al., 1970). Information on the escape of activity from the knee has been provided by, for example, Dunscombe et al. (1976), Gumpel et al. (1975), and Ramsey (1973). These studies have shown that over 5 days up to approximately $25 \%$ of the injected activity can escape, though lower figures are more usual. Measurements are not normally continued beyond 5 or 6 days.

It is of interest to supplement the information already obtained with more precise measurement of the activity distribution on the synovial membrane and with some indication of the medium-term retention of radioactivity in the knee. The opportunity to study these 2 aspects of the treatment arose when the synovial membranes of 2 patients who had received ${ }^{90} \mathrm{Y}$ silicate were surgically removed from the knee.

\section{Materials and methods}

Specimen A was obtained 1 day after administration of a trial dose of $37 \mathrm{MBq}(1 \mathrm{mCi})$ of ${ }^{90} \mathrm{Y}$ silicate (Radiochemical Centre code YAS 2P) in $15 \mathrm{ml}$ saline. The second synovial specimen (B) was

Accepted for publication 23 February 1979

Correspondence to Dr N. W. Ramsey, Department of Medical Physics, Charing Cross Hospital, Fulham Palace Road, London W6 8RF. removed 7 weeks after a therapeutic dose of 185 $\mathrm{MBq}(5 \mathrm{mCi})$ of ${ }^{90} \mathrm{Y}$ silicate in $17 \mathrm{ml}$ saline.

Autoradiographs of both specimens were produced on wrapped Kodak $x$-ray film, and the resultant optical densities were compared with those produced by known activities of ${ }^{90} \mathrm{Y}$ in a layer of water of approximately the same thickness, $3 \mathrm{~mm}$, as the synovial specimens. This comparison was carried out with a scanning microdensitometer.

The retention of activity in specimen $B$ was investigated by regular counting with a $2 \mathrm{~mm}$ thick $\mathrm{NaI}$ (T1) scintillator, the associated electronics of which accepted signals corresponding to an energy deposition greater than $20 \mathrm{keV}$ in the crystal. Measurements over a period of 8 weeks gave an indication of the half life of the activity in the sample and thereby assisted in its identification. Calibration of the detection system used a standard source similar to that employed for the film.

\section{Results}

Figs. 1 (a) and (b) show the autoradiographs produced by specimens removed 1 day and 7 weeks respectively after administration of the radionuclide. The non-uniformity in blackening of the films, which drops to the background level in some regions, is too large to be due to the influence of sample thickness on the amount and energy of the radiation reaching the films and must therefore result from an uneven distribution of activity on the specimens. This non-uniformity is perhaps hardly surprising in view of the well-known heterogeneity of tissue changes in rheumatoid arthritis (Gardner, 1978). 


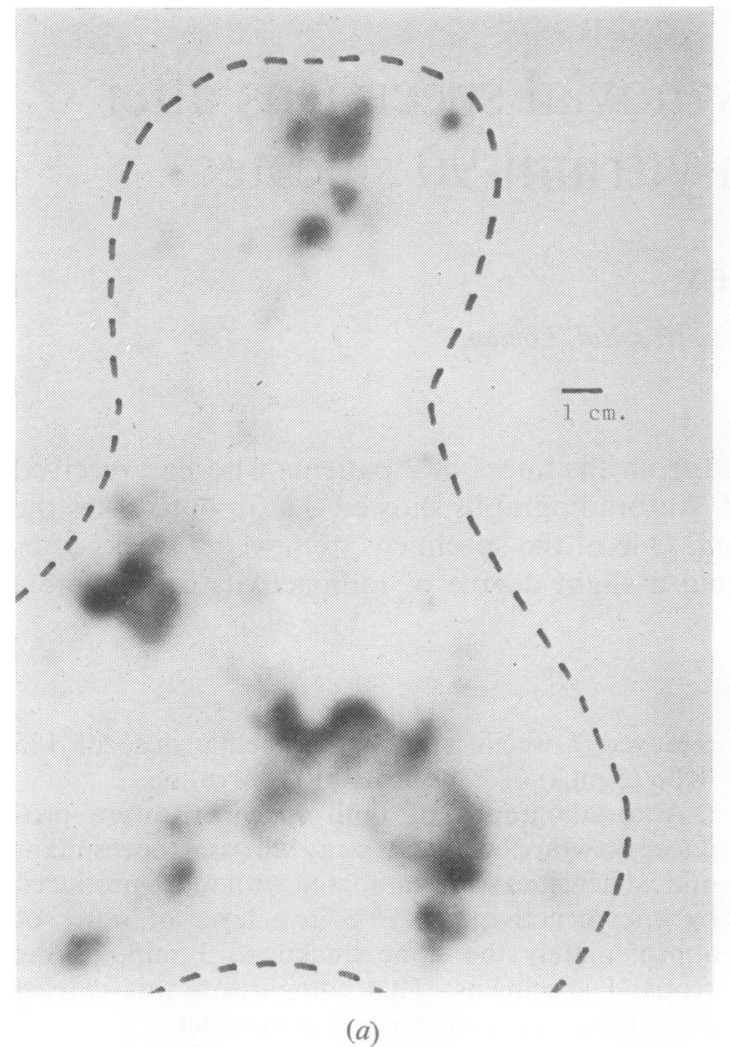

Fig. 1 Autoradiographs of the synovial specimens. A broken line indicates the edge of each specimen. The autoradiographs were made by placing the specimen in close contact with a wrapped x-ray film. (a) Sample removed one day after administration of $37 \mathrm{MBq}$ ( $1 \mathrm{mCi}$ ) of ${ }^{90} Y$ silicate. (b) Sample removed 7 weeks after administration of $185 \mathrm{MBq}(5 \mathrm{mCi})$ of ${ }^{90} \mathrm{Y}$ silicate.

Counting measurements indicated both that activity remained on the synovium and that, due to its half life, the most abundant radionuclide present was not ${ }^{90} \mathrm{Y}$. A sample of blood and knee fluid obtained from this patient at operation showed no measureable activity. Using the calibration described, the count rate from the synovial membrane was computed to be that which would have been observed from an ${ }^{90} \mathrm{Y}$ content of between 0.4 and $0.7 \mathrm{kBq}(0.01$ and $0.02 \mu \mathrm{Ci})$.

Analyses performed by the manufacturers identified the contaminants as ${ }^{91} \mathrm{Y}$ and ${ }^{88} \mathrm{Y}$. The level of these two nuclides present in the ${ }^{90} \mathrm{Y}$ colloid at the reference date (date of delivery), were $2.2 \times 10^{-3} \%$ activity of ${ }^{90} \mathrm{Y}$ as ${ }^{91} \mathrm{Y}$, and, for ${ }^{88} \mathrm{Y}, 1.4 \times 10^{-4} \%$ of ${ }^{90} \mathrm{Y} .{ }^{90} \mathrm{Sr}$ and ${ }^{89} \mathrm{Sr}$ were not identified at the limits of detection, which were respectively $2 \times 10^{-7}$ and

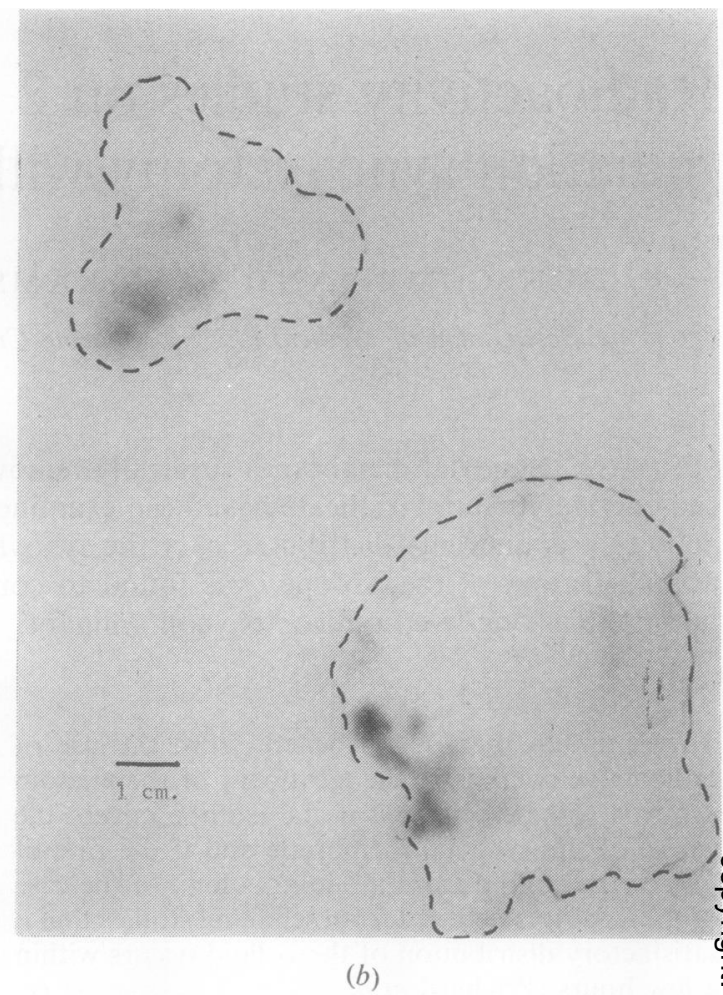

$2.6 \times 10^{-6 \%} \%$ activity of ${ }^{90} \mathrm{Y}$ on the reference date. As ${ }^{91} Y$ (half life 59 days) emits $\beta$ particles with an energy of $1.54 \mathrm{MeV}$ and ${ }^{88} \mathrm{Y}$ (half life 107 days) emits $\gamma$ rays, the main energies being $0.91 \mathrm{MeV}$ $(90 \%)$ and $1.85 \mathrm{MeV}(99 \%)$, the detection system employed would have been far more sensitive to ${ }^{91} \mathrm{Y}$, and it was therefore primarily this radionuclide as a contaminant and residual ${ }^{90} Y$ that were observed in the synovial specimen. The detection efficiency of the system would have been approximately the same for ${ }^{91} \mathrm{Y}$ and ${ }^{90} \mathrm{Y}$, and therefore the method of estimation of the activity in the specimen is valid for either and for a mixture of the 2 .

In common with most radiation synovectomy patients at this hospital the donor of specimen B had had her knee radioactivity measured for 6 days following administration of the isotope, with a decrease in the decay-corrected count rate of $14 \%$ being recorded in this period. If no further escape had occurred after the sixth day following administration of the isotope, then $2.9 \mathrm{kBq}(0.08 \mu \mathrm{Ci}){ }^{90} \mathrm{Y}$ and $2.5 \mathrm{kBq}(0.07 \mu \mathrm{Ci}){ }^{91} \mathrm{Y}$ should have been present in the specimen when counting began. In fact approximately $10 \%$ of the total amount expected was actually found. Although it is possible that not all the radioactivity in the knee was removed with the 
specimen, it would appear unlikely that $90 \%$ still remained in the knee. The possibility that radioactive material continues to escape from the knee joint after the period during which measurements over the knee were made suggests itself.

\section{Conclusions}

The autoradiographic studies indicate that activity is distributed unevenly over the synovial membrane. Scanning procedures, which indicate only the gross distribution, will not give this information. It is possible that the uneven distribution of the activity may result from spatial variations in the condition of the synovium arising from the disease process within the knee.

The amount of radioactive material present on the synovial membrane, 7 weeks after administration of the radionuclide, was less than expected from calculations of the decay, allowance being made for the known impurities in the injectate. The amount of ${ }^{91} \mathbf{Y}$, which forms the greater part of the impurity, when administered to the patient was approximately $2 \%$ of the maximum permissible body burden for that nuclide (ICRP, 1959).
The valuable assistance of the Radiochemical Centre, Amersham, in providing information relating to the contaminants in the ${ }^{90} \mathrm{Y}$ preparation is much appreciated.

We are indebted to Dr J. T. Scott, from whose patients the synovial specimens were obtained and to $\mathrm{Mr} \mathrm{A}$. K. Bhattacharyya for technical assistance with the radioactivity measurements.

\section{References}

Dunscombe, P. B., Bhattacharyya, A. K., and Dale, R. G. (1976). The assessment of the body distribution of yttrium90 ferric hydroxide during radiation synovectomy. British Journal of Radiology, 49, 372-373.

Gardner, D. L. (1978). Copeman's Textbook of the Rheumatic Diseases, Section III, p. 12. Edited by J. T. Scott. Churchill Livingstone: Edinburgh.

Gumpel, J. M., Beer, T. C., Crawley, J. C. W., and Farran, H. E. A. (1975). Yttrium-90 in persistent synovitis of the knee-a single centre comparison. The retention and extraarticular spread of four ${ }^{90} \mathrm{Y}$ colloids. British Journal of Radiology, 48, 377-381.

ICRP (1959). Report of Committee II on Permissible Dose for Internal Radiation.

Prichard, H. L., Bridgman, J. F., and Bleehen, N. M. (1970). An investigation of radioactive yttrium $\left({ }^{90} \mathrm{Y}\right)$ for the treatment of chronic knee effusions. British Journal of Radiology, 43, 466-470.

Ramsey, N. W. (1973). Retention of ${ }^{90} \mathrm{Y}$ in patients with rheumatoid arthritis. Annals of the Rheumatic Diseases, 32, Supplement, pp. 38-40. 